\title{
3 Research Suare

\section{In vitro and in vivo protective effect of Lotus seedpod extract against acetaminophen-induced liver injury}

Hsien-Chun Tseng

Chung Shan Medical University Hospital

Jen ying Hsu

Chung Shan Medical University https://orcid.org/0000-0001-5232-8428

Xiao-Yin Huang

Chung Shan Medical University

Hui-Hsuan Lin

Chung Shan Medical University

Jing-Hsien Chen ( $\nabla$ cjh0828@csmu.edu.tw )

\section{Research}

Keywords: Acetaminophen, liver injury, lotus seedpod extract, epigallocatechin, apoptosis, inflammation

Posted Date: June 15th, 2020

DOl: https://doi.org/10.21203/rs.3.rs-35355/v1

License: (1) This work is licensed under a Creative Commons Attribution 4.0 International License. Read Full License 


\section{Abstract \\ Background}

Acetaminophen (APAP) is one of the most widely used analgesic agents while overdose APAP will lead to severe hepatotoxicity. Lotus seedpod, a traditional herbal, is rich in polyphenol and has been shown to possess antioxidant, radioprotective and anti-cancer activities. This study examined the hepatoprotective role of lotus seedpod extracts (LSE) in vitro and in vivo.

\section{Methods}

Firstly, LSE or its main compound epigallocatechin (EGC) dose-dependently improved the survival of human hepatocyte HepG2 cells from APAP-induced loss of viability. In vivo study, the BALB/c mice were supplemented with or without LSE ( $1 \%$ and $2 \%$ ) during the 9-week treatment period in the presence or absence of APAP (i.p.; $400 \mathrm{mg} / \mathrm{kg}$ ) twice per week.

\section{Results}

In vitro study revealed that LSE or EGC showed potential in reducing APAP-induced occurrence of apoptosis confirmed by morphological and biochemical features, including an increase in the distribution of hypodiploid phase, apoptotic bodies formation, and caspases activation. Molecular data showed that antiapoptotic effects of LSE or EGC mediated via intrinsic, extrinsic and ASK 1/JNK apoptotic signaling pathways. Further data showed that LSE inhibited the APAP-induced the protein expression of iNOS to decrease inflammation. In vivo study showed that LSE treatments significantly decreased the serum levels of the hepatic enzyme markers GOT and GPT induced by APAP. LSE also inhibited the serum levels of inflammatory cytokines (IL-6 and IL-1 $\beta$ ) during APAP treatment. LSE at $1 \%$ significantly restored the decrease in glutathione (GSH) content and elevated the levels of antioxidant enzymes, including catalase and glutathione reductase (GRd), in the liver. Western blotting data demonstrated that LSE inhibited the expression of caspase $-3,-8,-9$ in APAP-induced liver injury.

\section{Conclusions}

LSE protected APAP-induced hepatotoxicity which could be a novo strategy for treatment.

\section{Introduction}

Lotus, (Nelumbo nucifera Gaertn.), also called Chinese water lily, is one of the perennial aquatic plants. Lotus is mainly grown in China, Japan, and Singapore. All parts of lotus, including lotus seed, flower, and root, possessed bioactivity and also known as one of the Chinese traditional medicines. Numerous phenolic compounds and alkaloids were identified in lotus [1,2]. Lotus seedpod is the by-product of lotus 
and often discarded during processing Chinese medicine. So far, the extract of lotus seedpod is the only part rich in proanthocyanidins [3]. Previous study reported that proanthocyanidins possessed anti-tumor effect [4], potent antioxidant capacity [5], inhibited advanced glycation-end products formation [3], and attenuated age-related deficits in cognitive functions [6]. In the latest study, the extract of lotus seedpod was investigated to protect LPS-induced hepatotoxicity through inhibiting pro-inflammatory cytokines and mediators expression [7].

Acetaminophen (APAP) is an analgesic and antipyretic agent which is broadly utilized either prescription or over-the-counter products. The maximum daily dose of APAP is $4 \mathrm{~g} /$ day for an adult. Under the therapeutic dose, APAP is an effective and safe drug for acute or chronic pain control which is recommended by WHO as the first option of pain control [8]. In chronic conditions such as cancer pain and osteoarthritis, patients required long-term high dose use of APAP [9], at the same time, increasing risk of APAP poisoning. Clinical studies indicated that high dose use of APAP for controlling chronic pain caused toxic effects to many organs as well as increased long-term mortality [10, 11]. The major APAP metabolism organ is in liver. Its poisoning resulted from depletion of glutathione and toxic metabolites accumulation [12]. Qingyun Bai et al. revealed that long-term high dose APAP administration to mice led to liver fibrosis [13]. N-acetyl cysteine (NAC) is currently the only one antidote FDA approved for treatment APAP poisoning. The study of antidote to protect from high dose use of APAP hepatotoxicity was limited. It is necessary to provide novo antidote to protect against the liver damage caused by long-term high dose APAP exposure.

The study aimed to investigate the protective effects of LSE and its possible mechanisms in overdose APAP-induced hepatotoxicity. In this study, HepG2 cells were treated with LSE and its major composition epigallocatechin (EGC) before APAP for exploring the protective effects and mechanisms. Further, animal model was designed to mimic overdose APAP administration for investigating the protection effects of LSE.

\section{Materials And Methods}

\section{Preparation of lotus seedpod extracts (LSE)}

The lotus seedpods (Nelumbo nucifera Gaertn.) obtained from Tainan, Taiwan. The lotus seedpods were removed seeds before extraction. The dried lotus seedpods $(100 \mathrm{~g})$ were macerated with hot water $\left(95^{\circ} \mathrm{C}\right.$, $4000 \mathrm{~mL}$ ) for $2 \mathrm{~h}$. The decoction was filtered, concentrated, and lyophilized as lotus seedpods extracts powder (LSE). Yield was approximately $17.2 \%$ of dried materials. The functional components were described in the previous study [7].

\section{Cell line and treatment}

The human hepatocellular carcinoma cell line HepG2 was purchased from the Bioresource Collection and Research Center (BCRC, Food Industry Research and Development Institute, Hsinchu, Taiwan, ROC). HepG2 cells were cultured in MEM medium supplemented with $2 \mathrm{mM} \mathrm{L-glutamine,} 1.5 \mathrm{~g} / \mathrm{L}$ sodium 
bicarbonate, $0.1 \mathrm{mM}$ non-essential amino acids, $1.0 \mathrm{mM}$ sodium pyruvate, $100 \mathrm{U} / \mathrm{mL}$ penicillin, $100 \mu \mathrm{g} / \mathrm{mL}$ streptomycin and $10 \%$ fetal bovine serum (FBS) at $37^{\circ} \mathrm{C}$ in a humidified atmosphere of $5 \%$ $\mathrm{CO}_{2}$. The HepG2 cells were seeded $\left(510^{5}\right.$ cells $/ \mathrm{mL}$ in MEM) in 6-well plates before treatment.

\section{Cell viability by trypan blue assay}

To determine the cytotoxicity of cell survival, trypan blue exclusion assay was performed. Cells were pretreated LSE $(2.5,5$, and $10 \mu \mathrm{g} / \mathrm{mL})$ or EGC $(4 \mu \mathrm{M})$ for $1 \mathrm{hr}$ and subsequently treated with APAP $(5 \mathrm{mM})$ for $24 \mathrm{hr}$. The number of cells were stained with trypan blue and counted the live cell to determine cell survival rate.

\section{DAPI stain assay}

HepG2 cells were seeded in $4.5 \times 10^{5}$ cells/well and cultured in 6-well plates. Cells were added LSE (2.5, 5 , and $10 \mu \mathrm{g} / \mathrm{mL})$ or EGC $(4 \mu \mathrm{M})$ before APAP $(5 \mathrm{mM})$. After $24 \mathrm{hr}$, the medium was removed and rinsed with warm PBS followed by $4 \%$ paraformaldehyde fixation for 30 min. Next, DAPI (Sigma-Aldrich, St Louis, MO, USA) was diluted with PBS and stained the nucleus for 30 min at room temperature in dark. Cell morphology was pictured by fluorescence microscopy and quantified by ImageJ software.

\section{Annexin V/propidium iodide (PI) stain assay}

The steps of Annexin V/PI stain assay mainly referred to FITC Annexin V Apoptosis Detection Kit (\#556547, BD Biosciences, San Jose, CA, USA). HepG2 cells were harvested, centrifuged, and resuspended with $1 \mathrm{X}$ binding buffer of the kit. $100 \mu \mathrm{L}$ cells suspension was transferred to $1.5 \mathrm{~mL}$ eppendorf and stained with $5 \mu \mathrm{L}$ annexin $V$ and $5 \mu \mathrm{L} \mathrm{PI}$ at room temperature for $15 \mathrm{~min}$ in dark room and then added 400 $\mu \mathrm{L} 1 \mathrm{X}$ binding buffer. Cell apoptosis was analysed by FACS101 flow cytometer (BD Biosciences, Franklin Lakes, NJ, USA).

\section{JC-1 assay for mitochondrial membrane depolarization analysis}

JC-1 stain was a cationic dye and accumulating in mitochondrial membrane based on membrane potential. Briefly, the medium was removed and HepG2 cells were washed by PBS after treatment. JC-1 stain was prepared in medium $(0.25 \mu \mathrm{g} / \mathrm{mL})$ and added $1 \mathrm{~mL}$ to each well for $15 \mathrm{~min}$. After incubation, cells were washed by PBC and evaluated by fluorescence microscopy.

\section{DCFH-DA assay for ROS analysis}

2',7'-dichlorofluorescein diacetate (DCF-DA) stain was diluted with medium and added firstly incubated for $1 \mathrm{hr}$. After removing DCF-DA stain, APAP (5 mM) with/without LSE $(2.5,5$, and $10 \mu \mathrm{g} / \mathrm{mL})$ or EGC $(4 \mu \mathrm{M})$ were added in HepG2 cells and incubated for $24 \mathrm{hr}$. Following the treatment, cells were harvested and suspended with PBS and counted using FACS101 flow cytometer.

\section{Mitochondria isolation}


Mitochondria isolated from HepG2 cells were using the Mitochondrial Isolation Kit from Thermo (Rockford, IL, USA) (\#89874). According to the manufacturer's protocol, HepG2 cells were harvested and added reagent $A$ and $B$ into eppendorf and vortex vigorously for $1 \mathrm{~h}$ at $4{ }^{\circ} \mathrm{C}$. The reagent $\mathrm{C}$ and protein inhibitor were then added into eppendorf and centrifuged $700 \mathrm{~g}$ for $10 \mathrm{~min}$ at $4{ }^{\circ} \mathrm{C}$. The pellet was homogenized again following adding protein inhibitor. Subsequently, the homogenized supernatant was centrifuged $12000 \mathrm{~g}$ for $5 \mathrm{~min}$ at $4{ }^{\circ} \mathrm{C}$ twice and the supernatant was contained mitochondria. Mitochondrial concentration was quantified by BCA assay.

\section{Animals and experimental design}

8 weeks old male Balb/c mice were obtained from the National Laboratory Animal Center (National Science Council, Taipei City, Taiwan). The use of mice was approved by the Chung Shan Medical University Animal Care Committee. All animals were housed in a constant condition of temperature (22 \pm $\left.2{ }^{\circ} \mathrm{C}\right)$ and humidity $(55 \pm 2 \%)$ room on a 12-h light/dark cycle. Mice were given access to food and water ad libitum for a week and randomly divided to five groups: control group, APAP group, APAP + $1 \%$ LSE group, APAP + $\%$ LSE group, and APAP + NAC group. Control group was fed with standard normal diets. APAP group was fed with standard normal diets for a week prior to APAP administration. APAP $+1 \% \mathrm{LSE}$ group and APAP + $2 \%$ LSE group were fed with normal diets blended with $1 \%$ or $2 \%$ LSE for a week prior to APAP application. APAP + NAC group was fed with normal diets contained NAC ( $600 \mathrm{mg} / \mathrm{kg}$ body weight/day) after administrated APAP. APAP was dissolved in warm saline and administered intraperitoneally with a single dose of $400 \mathrm{mg} / \mathrm{kg}$ body weight for twice a week for four groups except for the control group. The time scale of the animal experiment was depicted in Fig. 1. Mice body weights were measured every week during the experiment. To ensure the dosage of LSE, NAC, and APAP, the quantity was modified according to body weight. After eight weeks of treatment, mice were euthanized by carbon dioxide asphyxiation followed by exsanguination. The blood and liver samples were collected for further analysis.

\section{Histological assessments}

All groups were sacrificed and the right lobe of the liver was sectioned for histological assessments. Liver samples were fixed in $10 \%$ phosphate buffer formalin at least $24 \mathrm{hr}$, followed by a histological procedure to be embedded in paraffin. Sections of liver samples were sliced in $5 \mu \mathrm{m}$ and prepared to hematoxylineosin (H\&E) staining. Liver fibrosis was assessed by Masson's trichrome stain. Liver morphological changes were observed by light microscope (Leica DM4000B, Solms, Germany).

\section{Serum biochemical parameters and inflammatory cytokines}

Blood samples were centrifuged at $12000 \mathrm{rpm}$ for $15 \mathrm{~min}$ at $4{ }^{\circ} \mathrm{C}$ to determine serum biochemistry parameters. The serum level of GOT and GPT were determined by the medical laboratory in Chung Shan Medical University Hospital.

Inflammatory cytokines including TNF- $a$, IL-6, and IL-1 $\beta$ levels in liver tissue were quantified by ELISA MAX ${ }^{\text {TM }}$ Deluxe set (BioLegend, San Diego, CA, USA) and performed according to manufacturer's protocols. 


\section{Measurement of TBARS and antioxidant status in liver}

Liver samples were homogenized for lipid peroxidation and the analysis of antioxidant factors, including GSH, GRd, GPx, catalase, and SOD. GSH levels were determined with 5-thio-2-nitrobenzoic acid (TNB) and the procedures were described previously [14]. GRd activity in liver was measured according to the method of Carlberg and Mannervik [15]. According to the study of Lawrence and Burk, GPx activity has measured the degradation of NADPH in $3 \mathrm{~min}$ [16]. Catalase activity in liver was determined by hydrogen peroxide degradation rate according to a modification of the method proposed by Aebi [17]. SOD activity was performed with Superoxide Dismutase Assay Kit (\#706002) (Cayman, Ann Arbor, MI, USA). Lipid peroxidation was determined by TBARS. The method of TBAR assay was modified according to Ohkawa et al [18]. Malondialdehyde (MDA) is the product of lipid peroxidation which is generated by acidcatalyzed hydrolysis of 1,1,3,3-tetramethoxypropane. TBARS was compared with MDA standard curve.

\section{Immunoprecipitation (IP)}

Magnetic beads (Bio-Rad Laboratories, Inc., Hercules, CA, USA) were used for IP and separate specific protein targets. Magnetic beads were incubated with antibody FasL (for $10 \mathrm{~min}$ at room temperature. Then beads-antibody complex was incubated with target protein Fas. The beads were magnetized using the SureBeads rack and the supernatant was removed. The elution buffer was used for the eluting target protein and analyzed by western blot analysis.

\section{Protein extraction and western blot analysis}

Proteins from HepG2 cells and liver samples were homogenized in $1 \mathrm{~mL}$ RIPA lysis buffer containing a protease inhibitor cocktail (Pierce; Thermo Fisher Scientific, Rockford, IL, USA). Homogenized samples were centrifuged at $4^{\circ} \mathrm{C}, 12,000 \mathrm{rpm}$ for $10 \mathrm{~min}$. Total protein concentration was quantified by commercial BCA assay kit (Pierce; Thermo Fisher Scientific, Rockford, IL, USA). Protein extractions were separated by $8 \%$ or $10 \%$ SDS-poly-acrylamide gels and transferred to nitrocellulose membranes (Whatman, GE Healthcare, Freiburg, Germany). Basic western blotting procedure was described previously [19]. Primary antibodies against ASK1, Bax, Bcl2, caspase-3, caspase-8, COX2, COX4, cytochrome c, Fas, FasL, iNOS, MEK7, and NF-KB were purchased from Santa Cruz (CA, USA). Primary antibodies against Bid and caspase-9 were purchased from Novus Biologicals (Littleton, CO.). Primary antibodies against SAPK/JNK and phospho-SAPK/JNK were obtained from Cell Signaling (Beverly, MA). $\beta$-actin (A5441) was purchased from Sigma-Aldrich (St Louis, MO, USA) as a loading control. Chemiluminescence detection (Amersham Pharmacia Biotech, Little Chalfont, Bucks, UK) was used to quantified the blots. Quantification of the bands has measured the intensity of the immunoblot band and used ImageQuant ${ }^{\text {TM }}$ LAS 4000 mini (GE Healthcare Bio-Sciences AB, Uppsala, Sweden).

\section{Statistical analysis}

Statistical analysis was used Sigma Plot 10.0 software. The differences between mean values were analysed by Student's t-test. All experiment results were expressed as mean \pm SD. Differences with $p<$ 0.05 were considered to be significant. 


\section{Results}

\section{LSE protected hepatocytes from APAP-induced cytotoxicity and apoptosis in vitro}

First, APAP concentration was tested to HepG2 cells. The cell survival rate decreased in 5 mM APAP condition (Supplemental Fig. 1.). The cytotoxicity of LSE in various concentrations on HepG2 and showed that there was no cytotoxic effects on HepG2 cells in LSE 2.5, 5, and $10 \mu \mathrm{g} / \mathrm{mL}$ (Supplemental Fig. 2.). These concentrations of LSE were selected for further study. To determine if LSE could prevent APAP-induced injury, LSE was pre-treated in $2.5,5$, and $10 \mu \mathrm{g} / \mathrm{mL}$ or EGC at $4 \mu \mathrm{M}$ for an hour and then treated $5 \mathrm{mM}$ APAP for $24 \mathrm{~h}$. As shown in Fig. 1(A), pretreatment of LSE 5 and $10 \mu \mathrm{g} / \mathrm{mL}$ as well as EGC $4 \mu \mathrm{M}$ could significantly increase HepG2 survival rate 8-25\%. Apoptosis morphological changes were stained by DAPI. As shown in Fig. 1(B), except for the APAP group, morphological signs of apoptosis were observed in LSE and EGC groups. Compared with control, the apoptosis rate in the APAP group was significantly increased by $21 \%$. Pre-treat LSE or EGC significantly reduced $8-15 \%$ apoptotic cells compared with the APAP group (Fig. 1. (C)). These results presented that pre-treat LSE was tended to prevent APAP-induced cell apoptosis. Caspase 3, 8, and 9 protein expressions were further analyzed in each group. These three protein levels in the APAP group were significantly higher than the control group but significantly declined in $67 \%, 45 \%$, and $43 \%$ in $10 \mu \mathrm{g} / \mathrm{mL}$ LSE pretreatment group, respectively (Fig. 1 . (D)). EGC group got similar results with $10 \mu \mathrm{g} / \mathrm{mL}$ LSE group. Based on the results, we suggested that APAP-induced HepG2 cell death was related to apoptosis and could be reduced by LSE pretreatment.

\section{LSE inhibited APAP-induced apoptosis in extrinsic and intrinsic pathways}

To explore whether the Fas/FasL system was involved in APAP-induced liver injury, the interaction of Fas and FasL was analysed in each group. The results revealed that both Fas receptor and FasL expressions were increased in the APAP group when compared with the control group (Fig. 2. (A)). Compared with the APAP group, pre-treat $10 \mu \mathrm{g} / \mathrm{mL}$ LSE significantly decreased Fas receptors by $42 \%$ (Fig. 2. (A)). FasL levels were reduced by $8-15 \%$ when pre-treated with LSE 5 and $10 \mu \mathrm{g} / \mathrm{mL}$ and EGC $4 \mu \mathrm{M}$ (Fig. 2. (A)). Further, the immunoprecipitation assay verified that pretreatment of LSE and EGC could reduce Fas/FasL complex formation, especially in LSE $5 \mu \mathrm{g} / \mathrm{mL}$ (Fig. 2. (B)). These results demonstrated that LSE could protect APAP-induced hepatotoxicity through reduced Fas receptor and Fas ligand expression as well as interrupting Fas/FasL complex formation.

Next, the effects of LSE on the intrinsic pathway were analyzed. The mitochondrial depolarization was significantly increased by $262 \%$ in the APAP group compared with the control group (Fig. 2. (C)). Pretreatment LSE and EGC decreased depolarization, especially in LSE $10 \mu \mathrm{g} / \mathrm{mL}$ and EGC $4 \mu \mathrm{M}$, which significantly reduced $24 \%$ and $50 \%$ respectively compared with APAP group (Fig. 2. (C)). Pro-apoptosis protein level of Bax and tBid in toxic APAP concentration were enhanced and anti-apoptosis Bcl-2 level was repressed when compared with the control group (Fig. 2. (D)). While in LSE pre-treatment groups, Bax 
levels were significantly reduced by $36 \%, 33 \%$, and $33 \%$ respectively in three dosages compared with APAP group. tBid level in LSE groups was lower than APAP group in 33\%, 25\%, and 50\% (Fig. 2. (D)). Similar results could be found in the EGC group. Pre-treatment of LSE and EGC could increase Bcl2 expressions in $107 \%, 56 \%, 60 \%$, and $47 \%$ compared with APAP group (Fig. 2. (D)). Concurrently, cytochrome c level in the APAP group was reduced in mitochondria whereas increased in cytosol in toxic APAP treatment (Fig. 2. (E)). While pretreat of LSE and EGC could reverse the effects and significantly reduced by $32 \%, 26 \%$, and $33 \%$ compared with the APAP group (Fig. 2. (E)). Based on the above observations, pretreatment LSE could maintain mitochondrial integrity and prevent the occurrence of the intrinsic apoptotic pathway in hepatocytes.

\section{LSE attenuated APAP-induced inflammation and oxidative stress}

As shown in Fig. 3. (A), NF-KB, COX2, and iNOS protein levels in APAP group were significantly higher than the control group. While in LSE groups, NF-KB, COX2, and iNOS protein levels were lower than APAP group, especially in LSE $10 \mu \mathrm{g} / \mathrm{mL}$ group. EGC group got similar results with LSE groups. As shown in Fig. 3. (B), the ROS level in APAP group was significantly higher by $14 \%$ than in the control group. While pretreatment of LSE and EGC, the ROS level was lower 12-19\% than APAP group and restored to control group. In LSE groups, the ROS level in each group was lower than APAP group $12 \%, 14 \%$, and $12 \%$, respectively. In EGC group, we got similar results with LSE groups. The extensive oxidative stress and ROS production activated ASK1 and MEK 7 which regulate JNK phosphorylation [20]. In the present study, ASK1, MEK7, and the ratio of $p$-JNK1/JNK1 and p-JNK2/JNK2 expressions were significantly increased in APAP group compared with control group (Fig. 3. (C)). In pretreatment LSE groups, ASK1 and MEK7 levels were lower $8-39 \%$ than APAP group. In addition, the ratio of p-JNK1/JNK1 and p-JNK2/JNK2 were significantly reduced by $32-58 \%$ in LSE groups compared with APAP group (Fig. 3. (C)). There were showed similar results in EGC group.

\section{LSE ameliorated APAP-induced liver injury in vivo}

All group were sacrificed and liver tissues were collected for further analysis. The images of liver apparent in each group were depicted in Fig. 4 (A).The liver tissue from the control group presented with fresh color and smooth surface. In contrast, liver in APAP group presented with a rough surface. Liver samples from pre-treated $1 \%$ or $2 \%$ LSE groups and NAC group showed smoother surface and red color as control group when compared with APAP group. Hematoxylin \& eosin staining was used to assess liver histopathological alterations and the results were presented in Fig. 4. (B). Liver section in control group was presented with normal architecture. However, in the APAP group, liver section was observed with lesions and fibrotic changes. Pre-treated $1 \%$ or $2 \%$ LSE groups and NAC group showed more compressed tissue structure and reduced tissue lesions when compared with the APAP group. Liver fibrotic areas were observed by Masson's Trichrome stain and obviously reduced in 1\% or $2 \%$ LSE groups compared with APAP group (Fig. 4. (C)). Fibrotic areas could still be observed in NAC group although whose fibrosis was 
slightly milder than APAP group. According to the results, pre-treated low or high dose LSE could prevent high dose APAP-induced liver injury and fibrosis.

The serum GOT and GPT levels and inflammatory cytokines levels in each group were shown in Table 1. The GOT and GPT levels in APAP group were higher than control group $153 \%$ and $114 \%$, respectively, indicating that the liver function suffered damages for high dose acetaminophen treatment. In pretreatment $1 \%$ or $2 \%$ LSE group, serum GOT levels were significantly lower than APAP group $65 \%$ and $59 \%$, respectively. The GOT level in the NAC group was similar to APAP group. Pre-treatment $1 \%$ or $2 \%$ LSE and NAC treatment group could reduce GPT level $92 \%, 78 \%$, and $69 \%$, respectively. IL-6, IL-1 $\beta$, and TNF-a levels in APAP group were higher than control group. IL-6, IL-1 $\beta$, and TNF-a levels in APAP $+1 \%$ LSE group were significantly lower than APAP group in $63 \%, 82 \%$, and $75 \%$, respectively. While in APAP $+2 \%$ LSE group, IL-1 $\beta$ level was significantly lower than APAP group. Based on the results, we suggested that LSE could suppress inflammatory reactions through decrease inflammatory cytokine levels.

Table 1

Effect of LSE or NAC treatment on serum GOT and GPT levels and inflammatory cytokines of BALB/C mice $(n=10 /$ group $)$ induced by APAP injection.

\begin{tabular}{|c|c|c|c|c|c|}
\hline Groups & Control & APAP & APAP + $1 \%$ LSE & APAP + $2 \%$ LSE & APAP + NAC \\
\hline GOT (U/L) & $\begin{array}{l}174.2 \pm \\
38.2\end{array}$ & $\begin{array}{l}266.3 \pm 81.4 \\
\#\end{array}$ & $174.0 \pm 20.1^{\star}$ & $158.0 \pm 18.5^{\star}$ & $208.7 \pm 42.6$ \\
\hline GPT (U/L) & $61.2 \pm 7.5$ & $69.7 \pm 31.6$ & $64.3 \pm 15.6$ & $54.2 \pm 12.2$ & $48.7 \pm 15.8$ \\
\hline IL-6 (pg/mL) & $3.8 \pm 1.7$ & $13.0 \pm 3.6$ \#\# & $8.2 \pm 2.2$ * & $8.3 \pm 2.6$ & $5.5 \pm 3.3$ * \\
\hline $\mathrm{IL}-1 \beta(\mathrm{pg} / \mathrm{mL})$ & $88.9 \pm 18.1$ & $99.4 \pm 8.5$ & $81.7 \pm 13.4$ * & $70.1 \pm 13.1$ ** & $77.4 \pm 13.7$ ** \\
\hline $\begin{array}{l}\text { TNF-a } \\
(\mathrm{pg} / \mathrm{mL})\end{array}$ & $5.1 \pm 1.2$ & $5.2 \pm 0.9$ & $3.9 \pm 0.8$ * & $4.6 \pm 0.8$ & $5.3 \pm 0.8$ \\
\hline \multicolumn{6}{|c|}{ 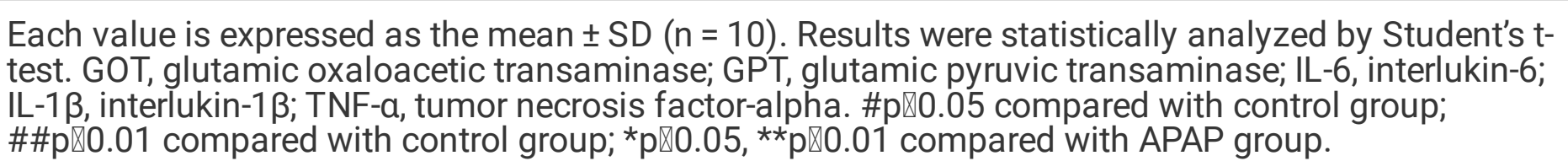 } \\
\hline
\end{tabular}

Antioxidant substances, except SOD, were decreased and oxidative stress was increased in APAP group compared with control group (Table 2.). In 1\% LSE group, the levels of GSH, GRd, and catalase were increased by $133 \%, 25 \%$, and $22 \%$, respectively, compared with APAP group. GRd level was significantly increased by $1 \%$ in $2 \%$ LSE group, compared with APAP group. While lipid peroxidation effect, in $1 \%$ or $2 \%$ LSE group, there were significantly reduced MDA levels in 52\% and $49 \%$ compared with APAP group. These results revealed that low dose LSE elevated antioxidant capacity, especially GSH, GRd, and catalase, to against APAP-induced oxidative stress. Besides, LSE could decrease lipid peroxidation by lowering MDA content. 
Table 2

Effect of LSE or NAC on the antioxidant substances and TBARS in APAP-induced liver injury in mice.

\begin{tabular}{|c|c|c|c|c|c|}
\hline Antioxidant substances & Control & APAP & $\begin{array}{l}\text { APAP + 1\% } \\
\text { LSE }\end{array}$ & $\begin{array}{l}\text { APAP + 2\% } \\
\text { LSE }\end{array}$ & $\begin{array}{l}\text { APAP + } \\
\text { NAC }\end{array}$ \\
\hline $\mathrm{SOD}(\mathrm{U} / \mathrm{mL} / \mathrm{mg}$ protein) & $\begin{array}{l}87.1 \pm \\
11.0\end{array}$ & $\begin{array}{l}102.2 \pm \\
15.8\end{array}$ & $\begin{array}{l}109.8 \pm \\
21.4\end{array}$ & $\begin{array}{l}103.1 \pm \\
22.5\end{array}$ & $\begin{array}{l}104.8 \pm \\
12.7\end{array}$ \\
\hline $\begin{array}{l}\text { Catalase ( } \mu \text { mol of } \mathrm{H}_{2} \mathrm{O}_{2} \\
/ \mathrm{min} / \mathrm{mg} \text { protein) }\end{array}$ & $13.5 \pm 2.7$ & $12.0 \pm 2.8$ & $14.6 \pm 1.4$ & $10.8 \pm 0.5$ & $12.6 \pm 3.2$ \\
\hline $\begin{array}{l}\text { GPx (nmol NADPH/min/mg } \\
\text { protein) }\end{array}$ & $\begin{array}{l}1090.7 \pm \\
101.0\end{array}$ & $\begin{array}{l}1057.0 \pm \\
88.4\end{array}$ & $\begin{array}{l}876.4 \pm \\
94.0\end{array}$ & $\begin{array}{l}820.9 \pm \\
78.9\end{array}$ & $\begin{array}{l}931.4 \pm \\
125.7\end{array}$ \\
\hline $\begin{array}{l}\text { GRd ( } \mathrm{nmol} \\
\mathrm{NADPH} / \mathrm{min} / \mathrm{mL} / \mathrm{mg} \text { protein) }\end{array}$ & $25.3 \pm 5.4$ & $23.5 \pm 4.6$ & $29.2 \pm 10.8$ & ${ }_{\star *}^{32.0} \pm 7.4$ & $30.4 \pm 9.7$ \\
\hline $\mathrm{GSH}(\mu \mathrm{M} / \mathrm{mg}$ protein) & $4.2 \pm 0.9$ & $3.3 \pm 0.9$ & $7.6 \pm 2.4^{\star \star}$ & $4.2 \pm 0.8$ & $3.8 \pm 1.0$ \\
\hline MDA (nmol/mg protein) & $1.0 \pm 0.1$ & $\begin{array}{l}1.4 \pm 0.3 \\
\#\end{array}$ & $0.7 \pm 0.3^{\star \star}$ & $0.7 \pm 0.1^{\star \star}$ & $1.2 \pm 0.3$ \\
\hline $\begin{array}{l}\text { Values are expressed as mea } \\
\text { compared with the APAP grol }\end{array}$ & $n=10$ & 0.05 & with th & ol grou & $<0.01$ \\
\hline
\end{tabular}

For confirming the anti-apoptosis effect of LSE in vivo, caspase 3, 8, and 9 expressions were analyzed in liver tissues. As in Fig. 5, the expression of caspase 3, 8, and 9 in APAP group were all significantly higher than control group. In $2 \%$ LSE group, all three protein levels were significantly lower than APAP group in $48 \%, 46 \%$, and $62 \%$, respectively. LSE treatment on high-APAP treatment showed the consistency with in vitro results and suggested that LSE pretreatment could prevent APAP-induced cell apoptosis.

\section{Discussion}

FDA has concerned in APAP-toxicity and subjected to Advisory Committees. APAP-induced hepatotoxicity is caused by its reactive metabolite $\mathrm{N}$-acetyl-p-benzoquinonimine (NAPQI) which is irreversibly quenched by the glutathione-SH group as a non-toxic metabolite and excreted into urine [21]. Unfortunately, overdose APAP made considerable NAPQI formation and consequently depleted GSH and covalently bond to $\mathrm{SH}$ group in cellular or mitochondrial protein to form protein-adducts leading to mitochondrial dysfunction [12, 22, 23]. In addition, overdose APAP exposure triggered the apoptosis pathway and inflammatory reactions $[24,25]$. The present study investigated the effects of LSE on high dose APAPinduced liver injury through in vitro and in vivo study. The results revealed that overdose APAP caused severe liver injury to mice and APAP-induced hepatotoxicity was involved with apoptosis, oxidative stress, and inflammatory response leading to cell death. Pretreatment of LSE inhibited the toxicity mentioned above to increase cell survive. Animal model was used to confirm multi hepatotoxicity on high dose APAP administration and found that pretreat LSE repressed liver fibrosis and provided protective effects against APAP-induced hepatotoxicity. 
In vitro study revealed that pretreat LSE reduced cell apoptosis rate which was involved with both extrinsic and intrinsic pathways. The extrinsic apoptosis pathway is initiated by death receptors, including TNF and Fas. The binding of Fas /FasL recruited caspase 8 to induce downstream factor of caspase 3 activity and resulting in cell death. Another signaling of caspase 8 induced Bid cleaving to tBid and cooperating with Bax. Both tBid and Bax were translocated to mitochondria and lead to mitochondrial permeability (Jaeschke et al., 2018). This process was crosslinked with an intrinsic apoptosis pathway. The intrinsic pathway was triggered by intracellular stimuli and consequently repressed anti-apoptosis proteins, Bcl-2, coupled with enhanced pro-apoptosis proteins Bax and Bid [26]. The present study showed that pretreatment LSE in high concentration inhibited not only Fas/FasL complex formation but also reduced Bid cleavage and cease the sequential activation. Mitochondrial membrane depolarization and the expression of cytochrome $c$ were increased in high APAP growth conditions. Mitochondrial membrane depolarization induced membrane permeability resulted in cytochrome $c$ and caspase 9 , which were resided in mitochondria, leaking out. [26, 27]. Pretreat LSE repressed mitochondrial depolarization to restore cytochrome $\mathrm{c}$ reside in mitochondria. Corresponding to in vitro study, caspase 3, 8, and 9 levels decreased in high dose LSE group which indicated that LSE pretreatment could against toxic dose APAP-induced apoptosis. These results demonstrated that LSE pretreatment could against APAP-induced hepatocyte apoptosis through repressing extrinsic and intrinsic apoptosis pathways.

Overwhelmed toxic metabolite NAPQI covalently bound to mitochondrial proteins and led to mitochondrial dysfunction following reactive oxide species generation, oxidative stress, and causing mitochondrial permeability transition $[28,29]$. Moreover, death receptor signaling transduction and inflammatory responses were sources of increased intracellular ROS [30]. Sustained oxidative stress and ROS production activated ASK1 and MEK7, one of the MAPK family proteins, and subsequently phosphorylated JNK to translocate to mitochondria [31]. Activated JNK led mitochondria to produce more ROS generation and self-amplified JNK activation pathway exacerbated mitochondrial permeability transition [32]. The deleterious cycle led to impair mitochondrial function and released pro-apoptotic proteins, including cytochrome $c$ and caspase from mitochondria [33]. As agree with previous studies, the present study observed that mitochondrial membrane depolarization and ROS formation were increased in toxic concentration of APAP, which probably indicated mitochondrial permeability transition. The present study revealed that pretreated LSE to HepG2 cells restored mitochondrial depolarization and reduced ROS generation. Besides, the expressions of ASK1, MEK7, and the ratio of p-JNK1/JNK1 and pJNK2/JNK2 were decreased in pretreat high concentration of LSE. The ability to defense oxidative stress of LSE from high dose APAP-induced hepatotoxicity was also confirmed by animal study. Liver lipid peroxidation in the APAP group was higher than in the control group, while there was significantly reduced in the pretreatment of $1 \%$ or $2 \%$ LSE group. In addition, the antioxidant capacity was elevated in $1 \%$ LSE group. We demonstrated that the pretreatment of LSE could against high dose APAP-induced hepatotoxicity through repressing oxidative stress and increasing antioxidant capacity.

Inflammation-mediated liver damages played a pivotal role in overdose APAP-induced hepatotoxicity. Inflammatory cytokines activated NF-KB to translocate to the nucleus and promoted pro-inflammatory 
enzyme expressions, including iNOS and COX2 [34]. According to the results, NF-kB, iNOS, and COX2 expressions were increased in HepG2 cells in high APAP concentration treatment but decreased in LSE or EGC pretreatment group. Similar results also revealed in in vivo study. In $1 \%$ or $2 \%$ LSE pretreatment group, IL-1 $\beta$ and IL- 6 levels in the liver were significantly reduced. These results suggested that LSE possessed the ability to ameliorate overdose APAP-induced liver inflammation.

\section{Conclusions}

In conclusion, the present study suggested that the pretreatment LSE effectively protected from high APAP-induced hepatotoxicity through inhibiting apoptosis, suppressing intracellular oxidative stress production, and decreasing inflammatory reactions. The study supposed that LSE is a prospective herbal medicine for APAP-induced liver injury.

\section{Abbreviations}

BCA, Bicinchonic acidGOT, glutamic oxaloacetic transaminase; GPT, glutamic pyruvic transaminase; IL-6, interlukin-6; IL-1 $\beta$, interlukin-1 $\beta$; TNF- $\alpha$, tumor necrosis factor-alpha; GSH, Glutathione; GRd, glutathione reduced; GPx, glutathione peroxidase; SOD, superoxide dismutase; TBARS, thiobarbituric acid reactive substances; MDA, malondialdehyde.

\section{Declarations}

\section{Acknowledgements}

Not applicable.

\section{Availability of data and materials:}

The datasets used and/or analysed during the current study are available from the corresponding author on reasonable request.

Ethics approval and consent to participate:

Not applicable.

Consent for publication:

Not applicable.

\section{Conflicts of Interest:}

The authors declare no conflict of interest. 


\section{Funding:}

This work was supported by the grant from Chung Shan Medical University Hospital (CSH-2017-C-029), Taichung City, Taiwan.

\section{Author Contributions:}

H.-H.L. and J.-H.C. conceived and designed the experiments; J.-Y.H., H.-C.T. and X.-Y.H. performed the experiments and analyzed the data; J.-Y.H., H.-H.L. and J.-H.C. wrote and edited the manuscript.

\section{References}

1. Paudel KR, Panth N. Phytochemical Profile and Biological Activity of Nelumbo nucifera. Evid Based Complement Alternat Med. 2015;2015:789124.

2. Limwachiranon J, Huang H, Shi Z, Li L, Luo Z. Lotus Flavonoids and Phenolic Acids: Health Promotion and Safe Consumption Dosages. Comprehensive Reviews in Food Science Food Safety. 2018;17(2):458-71.

3. Wu Q, Chen H, Lv Z, Li S, Hu B, Guan Y, Xie B, Sun Z. Oligomeric procyanidins of lotus seedpod inhibits the formation of advanced glycation end-products by scavenging reactive carbonyls. Food Chem. 2013;138(2-3):1493-502.

4. Duan $Y$, Zhang $H, X u F$, Xie B, Yang $X$, Wang $Y$, Yan Y. Inhibition effect of procyanidins from lotus seedpod on mouse B16 melanoma invivo and in vitro. Food Chem. 2010;122(1):84-91.

5. Kim M-J, Shin H-S. Antioxidative effect of lotus seed and seedpod extracts. Food Sci Biotechnol. 2012;21(6):1761-6.

6. Gong YS, Guo J, Hu K, Gao YQ, Xie BJ, Sun ZD, Yang EN, Hou FL. Ameliorative effect of lotus seedpod proanthocyanidins on cognitive impairment and brain aging induced by D-galactose. Exp Gerontol. 2016;74:21-8.

7. Tseng HC, Tsai PM, Chou YH, Lee YC, Lin HH, Chen JH. In Vitro and In Vivo Protective Effects of Flavonoid-Enriched Lotus Seedpod Extract on Lipopolysaccharide-Induced Hepatic Inflammation. Am J Chin Med. 2019;47(1):153-76.

8. Organization WH: Cancer pain relief: with a guide to opioid availability: World Health Organization; 1996.

9. Ennis ZN, Dideriksen D, Vaegter HB, Handberg G, Pottegard A. Acetaminophen for Chronic Pain: A Systematic Review on Efficacy. Basic Clin Pharmacol Toxicol. 2016;118(3):184-9.

10. Huang HS, Ho CH, Weng SF, Hsu CC, Wang JJ, Su SB, Lin HJ, Huang CC. Long-term mortality of acetaminophen poisoning: a nationwide population-based cohort study with 10-year follow-up in Taiwan. Scand J Trauma Resusc Emerg Med. 2018;26(1):5. 
11. McCrae JC, Morrison EE, Maclntyre IM, Dear JW, Webb DJ. Long-term adverse effects of paracetamol - a review. Br J Clin Pharmacol. 2018;84(10):2218-30.

12. James LP, Mayeux PR, Hinson JA. Acetaminophen-induced hepatotoxicity. Drug Metab Dispos. 2003;31(12):1499-506.

13. Bai Q, Yan H, Sheng Y, Jin Y, Shi L, Ji L, Wang Z. Long-term acetaminophen treatment induced liver fibrosis in mice and the involvement of Egr-1. Toxicology. 2017;382:47-58.

14. Eyer P, Podhradský D. Evaluation of the micromethod for determination of glutathione using enzymatic cycling and Ellman's reagent. Anal Biochem. 1986;153(1):57-66.

15. Carlberg I, Mannervik B. Glutathione reductase. Methods Enzymol. 1985;113:484-90.

16. Lawrence RA, Burk RF. Glutathione peroxidase activity in selenium-deficient rat liver. Biochem Biophys Res Commun. 1976;71(4):952-8.

17. Aebi H. Catalase in vitro. Methods Enzymol. 1984;105:121-6.

18. Ohkawa H, Ohishi N, Yagi K. Assay for lipid peroxides in animal tissues by thiobarbituric acid reaction. Anal Biochem. 1979;95(2):351-8.

19. Hsu JY, Lin HH, Hsu CC, Chen BC, Chen JH. Aqueous Extract of Pepino (Solanum muriactum Ait) Leaves Ameliorate Lipid Accumulation and Oxidative Stress in Alcoholic Fatty Liver Disease. Nutrients 2018, 10(7).

20. Shen HM, Liu ZG. JNK signaling pathway is a key modulator in cell death mediated by reactive oxygen and nitrogen species. Free Radic Biol Med. 2006;40(6):928-39.

21. Yan M, Huo Y, Yin S, Hu H. Mechanisms of acetaminophen-induced liver injury and its implications for therapeutic interventions. Redox Biol. 2018;17:274-83.

22. Du K, Ramachandran A, Weemhoff JL, Chavan H, Xie Y, Krishnamurthy P, Jaeschke H: Editor's Highlight: Metformin Protects Against Acetaminophen Hepatotoxicity by Attenuation of
Mitochondrial Oxidant Stress and Dysfunction. Toxicol Sci 2016, 154(2):214-226.

23. Kushnareva Y, Murphy AN, Andreyev A. Complex I-mediated reactive oxygen species generation: modulation by cytochrome $c$ and NAD (P) + oxidation-reduction state. Biochem J. 2002;368(Pt 2):545-53.

24. Knight TR, Jaeschke H. Acetaminophen-induced inhibition of Fas receptor-mediated liver cell apoptosis: mitochondrial dysfunction versus glutathione depletion. Toxicol Appl Pharmacol. 2002;181(2):133-41.

25. Jaeschke H, Duan L, Akakpo JY, Farhood A, Ramachandran A. The role of apoptosis in acetaminophen hepatotoxicity. Food Chem Toxicol. 2018;118:709-18.

26. Suhaili SH, Karimian H, Stellato M, Lee TH, Aguilar MI. Mitochondrial outer membrane permeabilization: a focus on the role of mitochondrial membrane structural organization. Biophys Rev. 2017;9(4):443-57.

27. Gillies LA, Kuwana T. Apoptosis regulation at the mitochondrial outer membrane. J Cell Biochem. 2014;115(4):632-40. 
28. Du K, Ramachandran A, Jaeschke H. Oxidative stress during acetaminophen hepatotoxicity: Sources, pathophysiological role and therapeutic potential. Redox Biol. 2016;10:148-56.

29. Qiu Y, Benet LZ, Burlingame AL. Identification of the hepatic protein targets of reactive metabolites of acetaminophen in vivo in mice using two-dimensional gel electrophoresis and mass spectrometry. $J$ Biol Chem. 1998;273(28):17940-53.

30. Jaeschke H, McGill MR, Ramachandran A. Oxidant stress, mitochondria, and cell death mechanisms in drug-induced liver injury: lessons learned from acetaminophen hepatotoxicity. Drug Metab Rev. 2012;44(1):88-106.

31. Karthivashan G, Arulselvan P, Fakurazi S: Pathways involved in acetaminophen hepatotoxicity with specific targets for inhibition/downregulation. RSC Advances 2015, 5(76):62040-62051.

32. Hanawa N, Shinohara M, Saberi B, Gaarde WA, Han D, Kaplowitz N. Role of JNK translocation to mitochondria leading to inhibition of mitochondria bioenergetics in acetaminophen-induced liver injury. J Biol Chem. 2008;283(20):13565-77.

33. Moles A, Torres S, Baulies A, Garcia-Ruiz C, Fernandez-Checa JC. Mitochondrial-Lysosomal Axis in Acetaminophen Hepatotoxicity. Front Pharmacol. 2018;9:453.

34. da Silva BS, Rodrigues GB, Rocha SW, Ribeiro EL, Gomes FO, AK ES, Peixoto CA. Inhibition of NFkappaB activation by diethylcarbamazine prevents alcohol-induced liver injury in C57BL/6 mice. Tissue Cell. 2014;46(5):363-71.

\section{Supplementary Figure Legends}

Supplementary Materials: Figure S1: The HepG2 cell viability of APAP in variant concentrations. Figure S2: The HepG2 cell viability of LSE in variant concentrations.

\section{Figures}


A

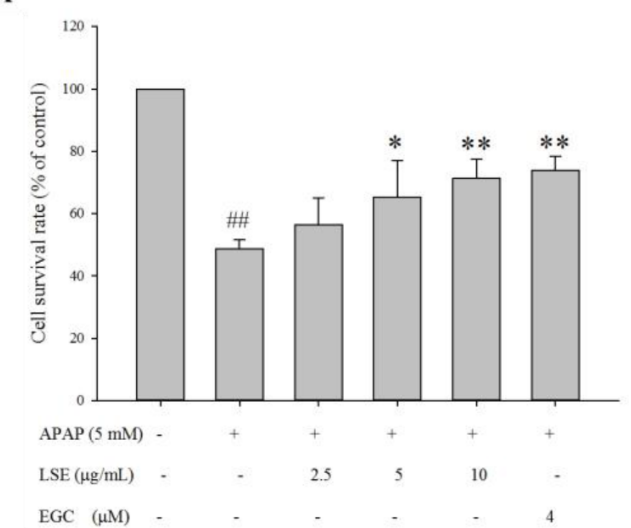

C
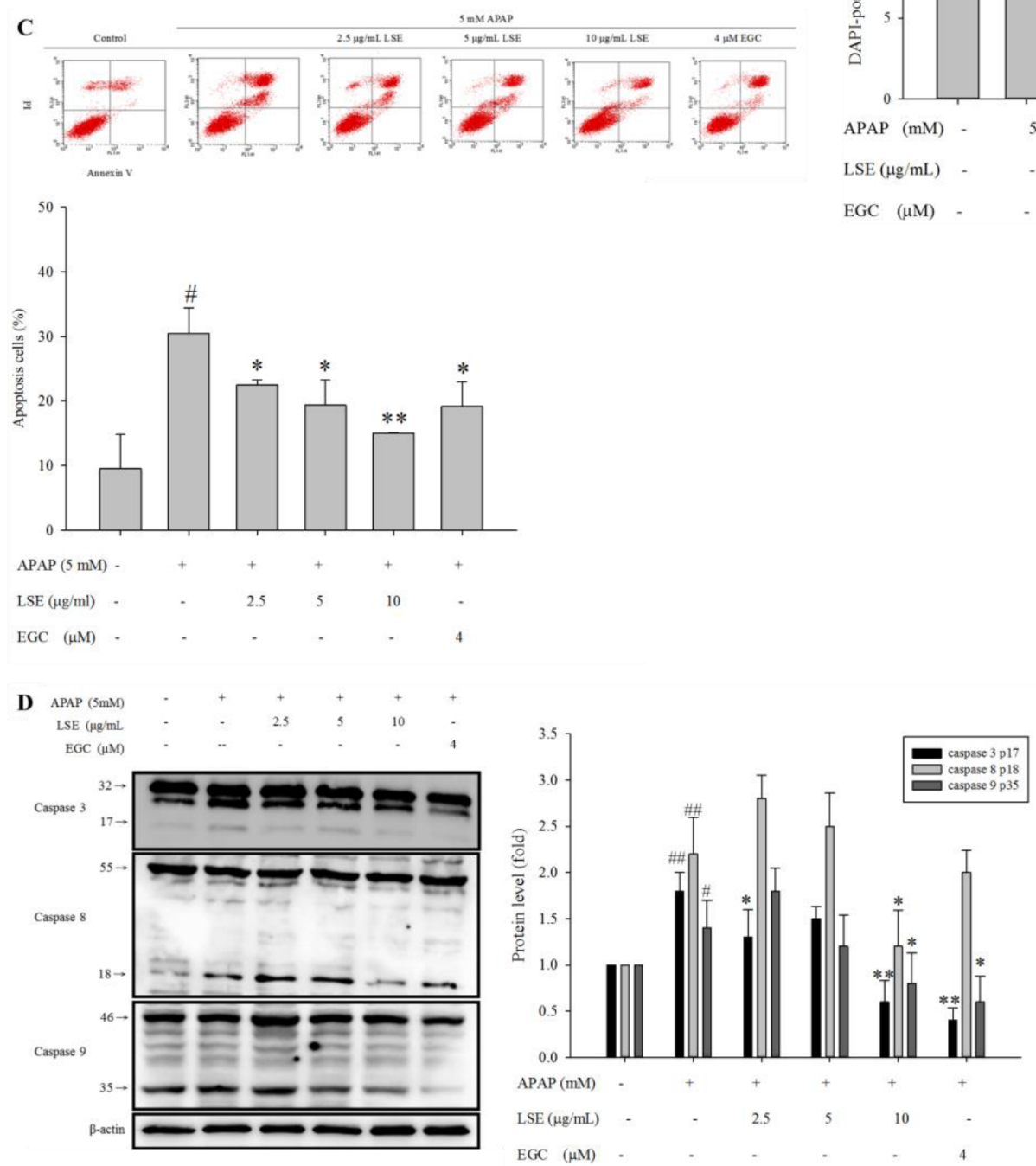
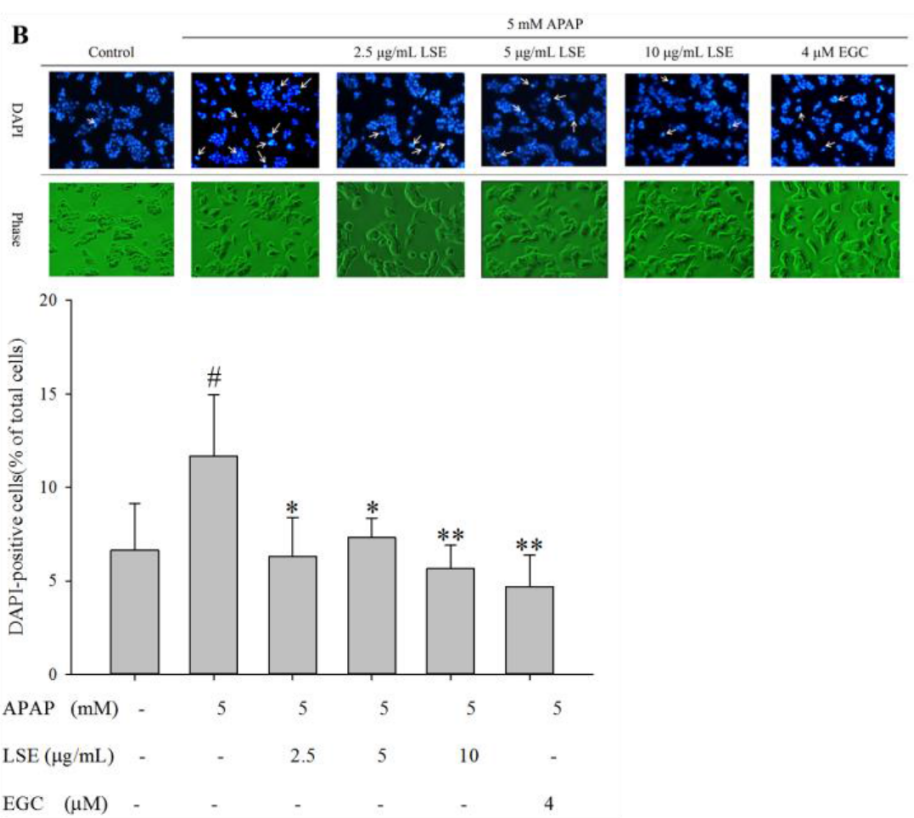

EGC $(\mu \mathrm{M})$ 
double staining after treating LSE or EGC with or without APAP for $24 \mathrm{~h}$. Upper right indicates late apoptotic cells (Annexin V and PI positive). (D) The protein levels of caspase 3, 8, and 9 of each group were analyzed by western blotting. All data were presented as means \pm SD of three independent experiments. $\# p<0.05, \# \# p<0.01$ compared with the control group. ${ }^{*} p<0.05,{ }^{*} p<0.01$ compared with the APAP group.

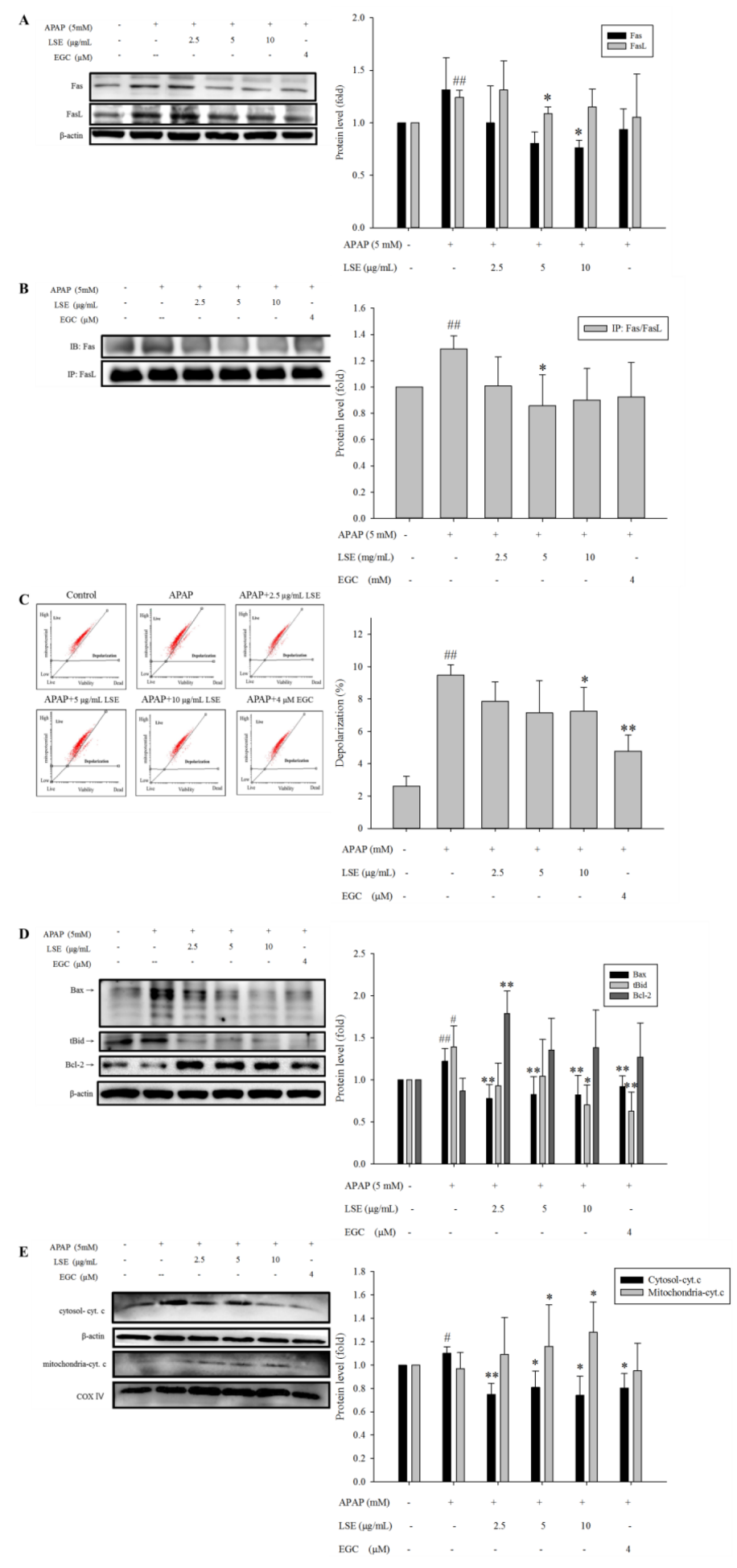

Figure 2 
Effect of LSE on extrinsic and intrinsic apoptotic pathways in APAP -treated HepG2 cells. HepG2 cells were treated with or without $\operatorname{LSE}(2.5,5,10 \mu \mathrm{g} / \mathrm{ml})$ or EGC $(4 \mu \mathrm{M})$ for $24 \mathrm{~h}$ in the presence or absence of APAP ( $5 \mathrm{mM})$. (A) The protein levels of Fas and FasL were analyzed by Western blotting. (B) The protein levels of Fas and FasL were analyzed by IP. The cell extracts were IP with FasL. The precipitated complex was examined for immunoblotting (IB) using Fas antibody. (C) The mitochondrial membrane depolarization were assayed by JC-1staining with flow cytometry. Percentage of mitochondrial depolarization is plotted for various treatment groups. (D) The protein levels of Bax, tBid and Bcl-2 were analyzed by western blotting. (E) The protein levels of cytosol and mitochondria cytochrome $c$ were analyzed by western blotting. $\beta$-actin and COX 4 were served as an internal control of cell cytosol and mitochondria. All data were presented as means \pm SD of three independent experiments. $\# p<0.05$, $\# \# p<0.01$ compared with the control group. ${ }^{*} p<0.05,{ }^{* \star} p<0.01$ compared with the APAP group. 


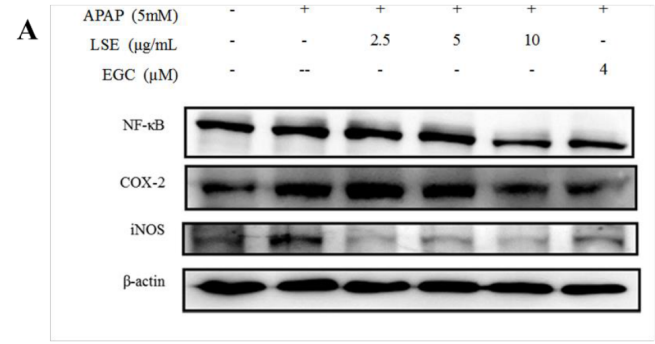

B

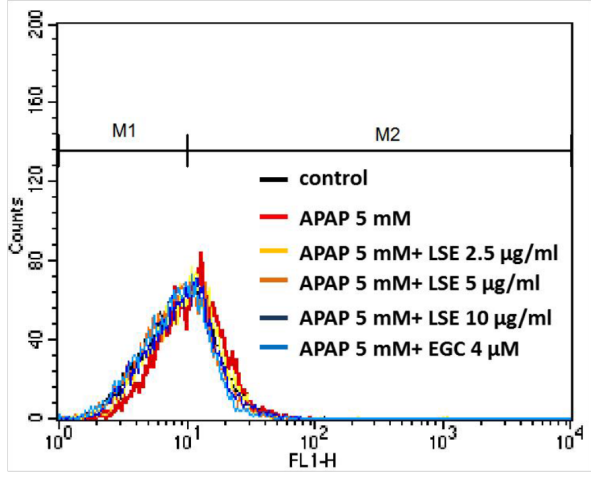

C

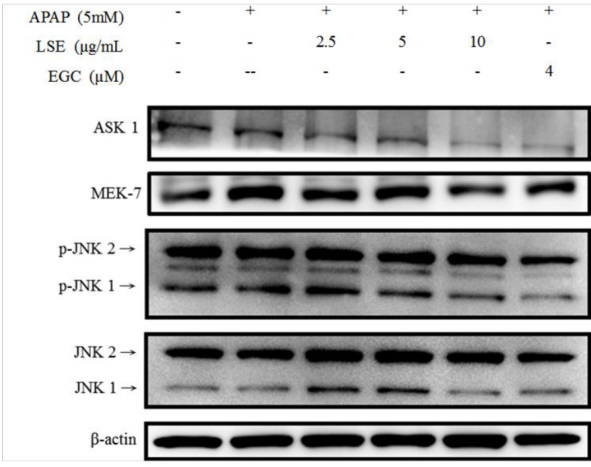

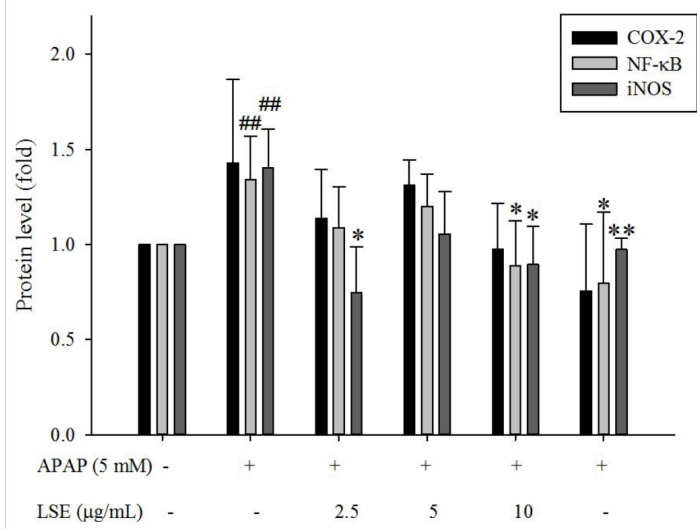
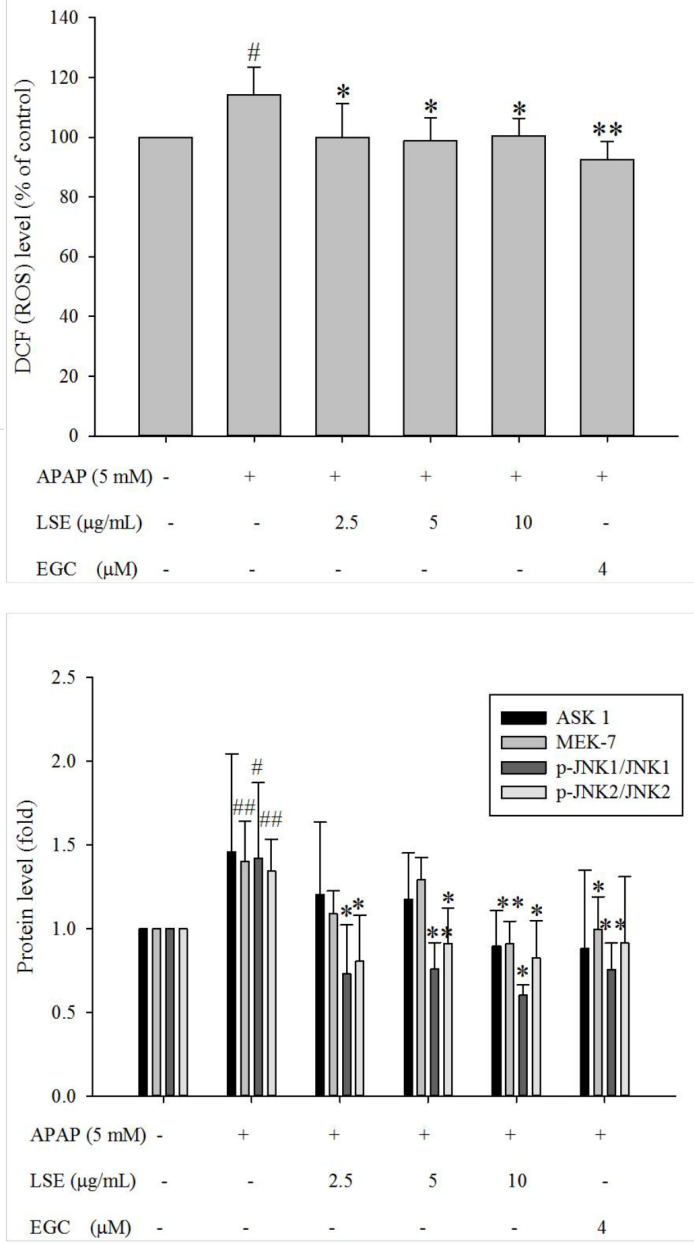

Figure 3

Effect of LSE on the expressions of inflammation and oxidative stress related proteins in APAP-induced HepG2 cells. HepG2 cells were treated with or without LSE $(2.5,5,10 \mu \mathrm{g} / \mathrm{ml})$ or EGC $(4 \mu \mathrm{M})$ for $24 \mathrm{~h}$ in the presence or absence of APAP ( $5 \mathrm{mM})$. (A) The protein levels of COX-2, NF-KB and iNOS were analyzed by Western blotting. $\beta$-actin served as an internal control of cell cytosol. The quantitative data were resented as means \pm SD of three independent experiments. \#\#p $<0.01$ compared with the control group. ${ }^{*} p<0.05$, 
${ }^{\star *} \mathrm{p}<0.01$ compared with the APAP group. (B) The ROS were assayed by DCFH-DA staining with flow cytometry. ROS levels were presented as percentage of DCF-positive cells divided by the total number of cells. (C) The protein levels of ASK 1/MEK-7/JNK were analyzed by Western blotting. $\beta$-actin served as an internal control of cell cytosol. The quantitative data were presented as means \pm SD of three independent experiments. $\# p<0.05, \# \# p<0.01$ compared with the control group. ${ }^{*} p<0.05,{ }^{*} p<0.01$ compared with the APAP group.

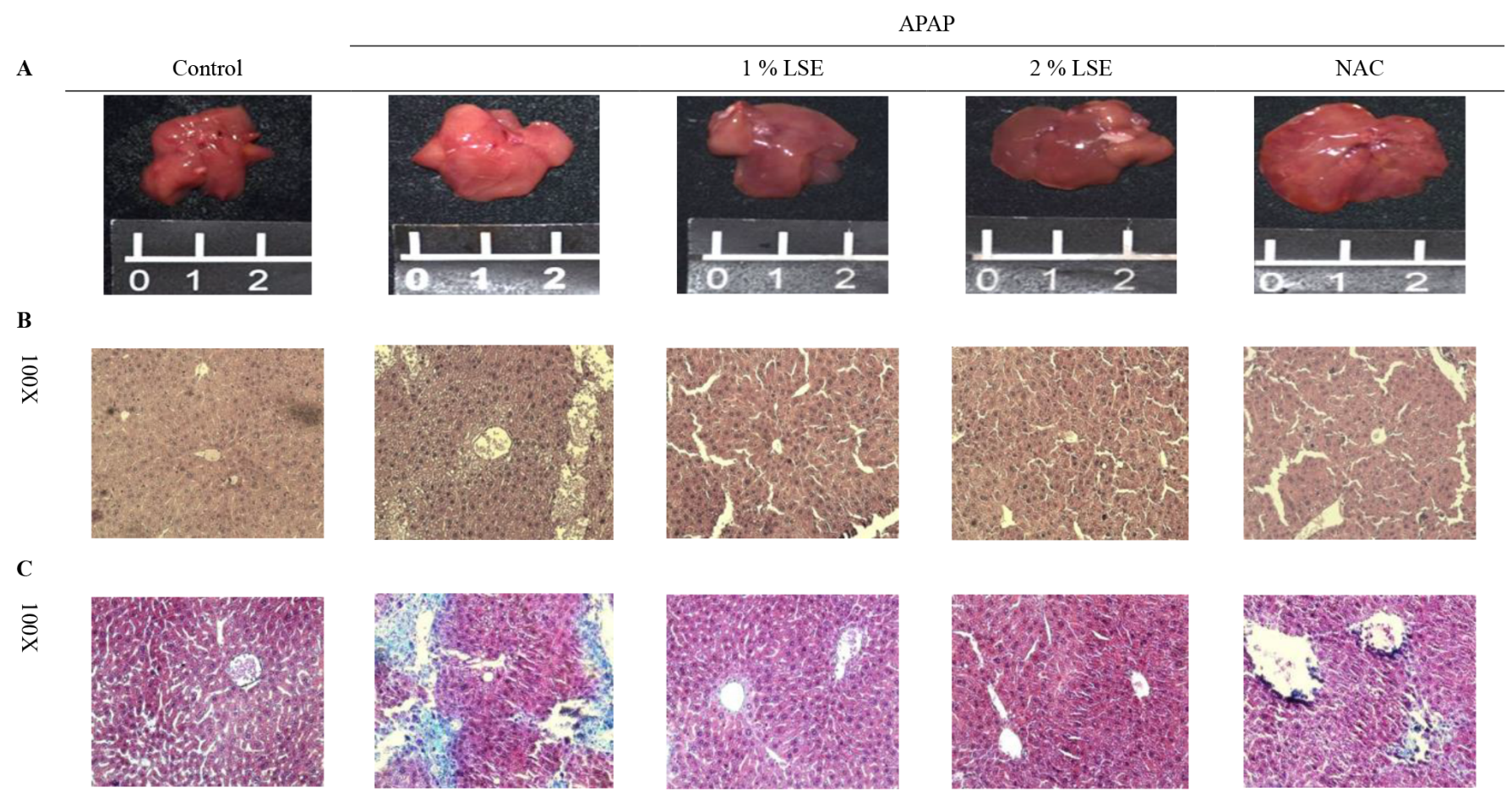

Figure 4

Effect of LSE on liver histopathology after by APAP injection in BALB/c mice. The BALB/c mice were treated with or without LSE (1\% and $2 \%$ ) or NAC for 9-weeks in the presence or absence of $400 \mathrm{mg}$ APAP/kg bw (i.p.) twice per week. (A) Images of liver tissue from mice of indicated groups. (B) H \& Estained liver sections of indicated groups. (C) Masson's trichrome stained liver sections of indicated groups. Each liver section was represented in 100X images from different groups ( $n=10 /$ group). 


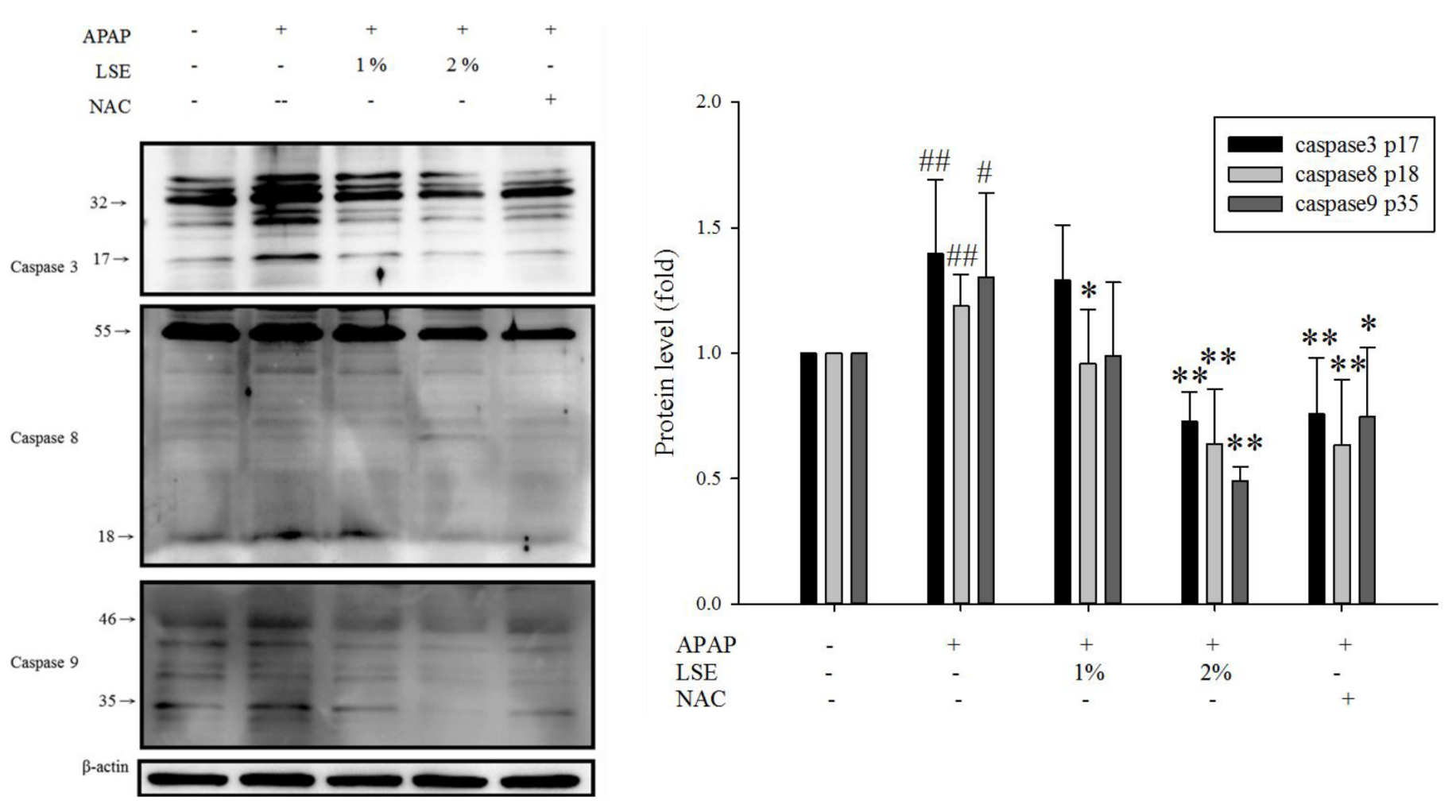

Figure 5

Effect of $1 \%$ or $2 \%$ LSE or NAC on caspase 3,8 , and 9 expression in APAP-induced BALB/c mice after 9week treatment. (A) The protein levels of caspase-3,-8,-9 were analyzed by western blotting. (B) The quantitative data were presented as means $\pm S D$ of three independent experiments. $\# p<0.05, \# \# p<0.01$ compared with the control group. ${ }^{\star} p<0.05,{ }^{*} \mathrm{p}<0.01$ compared with the APAP group.

\section{Supplementary Files}

This is a list of supplementary files associated with this preprint. Click to download.

- supplement9.tif

- supplement10.tif 